\title{
ГЕОХИМИЧЕСКИЕ ОСОБЕННОСТИ ОРГАНИЧЕСКОГО ВЕЩЕСТВА В ДОННЫХ ОТЛОЖЕНИЯХ ЛАГУНЫ ИВАШКИНОЙ (БЫКОВСКИЙ ПОЛУОСТРОВ, МОРЕ ЛАПТЕВЫХ)
}

Гершелис (Панова) Елена Владимировна',

elenapanova@tpu.ru

Гончаров Иван Васильевич',

GoncharovlV@tomsknipi.ru

Дударев Олег Викторовиче, dudarev@poi.dvo.ru

\author{
Рубан Алексей Сергеевич', \\ ruban@tpu.ru
}

\author{
Перевертайло Татьяна Геннадьевна', \\ ptg@tpu.ru
}

\author{
Щербакова Ксения Павловна², \\ ksushok7@mail.ru
}

Шахова Наталья Евгеньевна', shahova@tpu.ru

Семилетов Игорь Петрович,1, ipsemiletov@alaska.edu

\footnotetext{
1 Национальный исследовательский Томский политехнический университет, Россия, 634050, г. Томск, пр. Ленина, 30.

2 Тихоокеанский океанологический институт им. В.И. Ильичева Дальневосточного отделения Российской Академии наук, Россия, 690041, г. Владивосток, ул. Балтийская, 43
}

Актуальность. В настоящее время для прогнозирования глобальных климатических изменений особое значение имеет исследование природных механизмов функционирования арктической биогеохимической экосистемы с применением различных методов и аналитических подходов. Органическое вещество современных донных осадков, аккумулирующее гетерогенные сигналы различных процессов транспорта и трансформации углерода, является индикатором уникальных особенностей седиментогенеза и диагенеза осадков. Использование наборов высокоточных геохимических инструментов позволяет получить важную информацию о вкладе аллохтонной и автохтонной компоненты в состав органического вещества и таким образом внести вклад в понимание отдельных элементов современного арктического цикла углерода.

Цель исследования заключается в определении литологических и органо-геохимических особенностей отложений, накопленных в специфических лагунных условиях прибрежной части моря Лаптевых (Ивашкина лагуна, Быковский полуостров).

Материалы и методы. Объектом исследования был выбран разрез осадков в районе дельты реки Лена. Для оценки изменчивости молекулярного состава органического вещества в процессе накопления толщ осадков был исследован 18-метровый интервал керна скважины VD-13, пробуренной в центральной части Ивашкиной лагуны во время весенней арктической экспедиции 2013 г. Для образцов были определены их гранулометрические характеристики, а также проведены пиролитические и хроматомасс-спектрометрические исследования. Показано, что повышенное содержание органического углерода ( $\left.C_{\text {орг }}\right)$ в разрезе приурочено к пелитовой фракции осадков. Распределение н-алканов характеризуется доминированием высокомолекулярных нечетных гомологов, что указывает на повсеместно определяющий вклад высшей наземной растительности в формирование органического вещества, аккумулируемого в осадках. Тем не менее, вклад потенциально миграционной органической компоненты не исключен, так как для ряда образцов отмечается присутствие низкомолекулярной фракции н-алканов. Результаты пиролитического анализа образцов указывают на резкую изменчивость содержания $C_{\text {орг }}$ и летучих органических соединений с глубиной.

\section{Ключевые слова:}

Восточно-Сибирский шельф, донные осадки, органический углерод, пиролиз, современные осадки.

\section{Введение}

Моря Восточной Арктики (МВА) характеризуются рядом специфических особенностей, что способствует активному росту интереса научного общества к всестороннему изучению их природы. Одной из таких особенностей является наиболее ши- рокий и мелководный в Мировом океане шельф, на более чем 80 \% территории которого распространены реликтовые подводные мерзлые толщи [1-4]. Согласно оценкам, их мощность в прибрежной зоне достигает 500 м [5]. Результаты многолетних исследований убедительно доказывают, что шельф 
МВА выступает не только уникальным хранилищем огромного количества органического углерода $\left(\mathrm{C}_{\text {орг }}\right)$ в различных формах, но также представляет собой важнейшее звено арктической климатической системы, являясь основным источником парниковых газов - диоксида углерода $\left(\mathrm{CO}_{2}\right)$ и метана - в арктическом регионе [1, 6-12]. Кроме того, транспорт и трансформация эрозионного $\mathrm{C}_{\text {орг }}$ определяют биогеохимический и седиментационный режим в МВА [13-15], что благодаря окислению ОУ до двуокиси углерода также проявляется в экстремальной асидификации вод [16].

Прогрессирующая деградация прибрежной и подводной мерзлой толщи [17] приводит к высвобождению и вовлечению в современный биогеохимический цикл гигантских объемов $\mathrm{C}_{\text {орг }}$, в результате чего вода арктических морей обогащается $\mathrm{CO}_{2}$, а в атмосферу выделятся огромное количество метана [1]. Потому в настоящее время особое значение имеет исследование природных механизмов функционирования арктической биогеохимической экосистемы с применением различных методов и аналитических подходов [18-21]. Органическое вещество (OB) современных донных осадков, аккумулирующее гетерогенные сигналы различных процессов транспорта и трансформации углерода, является индикатором уникальных особенностей седиментогенеза и диагенеза осадков. Использование наборов высокоточных геохимических инструментов позволяет получить важную информацию о вкладе аллохтонной и автохтонной компоненты в состав ОВ, уточнить особенности его распределения, в том числе в зонах документированной активной разгрузки восходящих газовых флюидов и таким образом внести вклад в понимание отдельных элементов современного арктического цикла углерода.

Целью данной работы являлось исследование некоторых геохимических особенностей отложений Ивашкиной лагуны, расположенной в юговосточной части моря Лаптевых на южном побережье Быковского полуострова.

\section{Район работ, материалы и методы исследований}

В настоящей работе объектом исследования был выбран разрез специфических осадков в пределах лагуны, расположенной юго-восточнее дельты реки Лена. Для оценки изменчивости молекулярного состава ОВ в процессе накопления осадочных толщ был исследован керн скважины VD-13 в интервале 0-18 м, пробуренной в центральной части Ивашкиной лагуны во время весенней арктической экспедиции 2013 г. (рис. 1). Лагуна размером $2 \times 2,5 \mathrm{kм}$, расположенная в юго-восточной части Быковского полуострова, представляет собой почти замкнутую термокарстовую котловину, северный и восточный берега которой сложены поздненеоплейстоценовыми отложениями ледового комплекса, а западный берег - голоценовыми аласными отложениями [22]. Отбор керна из скважины VD-13 осуществлялся с помощью установки разведочного бурения УРБ-4Т по методике, описанной в [17]. Глубина забоя скважины от поверхности дна составила 41,1 м.

Гранулометрический состав осадочного материала изучался на лазерном дифракционном анализаторе "Analysette 22 Fritsch» в лаборатории арктических исследований ТОИ ДВО РАН. Литологическая типизация осадков проводилась на основе трехкомпонентной классификации ТОИ ДВО РАН по соотношению содержания фракций песка (1-0,1 мм), алеврита $(0,1-0,01 \mathrm{~mm})$ и пелита $(<0,01 \mathrm{мм})$ [23].

Для проведения анализов образцы размораживали при комнатной температуре в течение суток и далее гомогенизировали. Затем образцы доводили до постоянного веса в сушильном шкафу при температуре $45{ }^{\circ} \mathrm{C}$. Выделение битумоида проводили хлороформом в аппарате Сокслета в течение 14 часов. Далее экстракты концентрировались на роторном испарителе и сушились до постоянного веса.

Общее содержание органического углерода, содержание минерального углерода, содержание легколетучих органических соединений, количество продуктов деструкции биогеополимеров в осадках по образцам керна определяли на пиролизаторе «Rock-Eval 6 Turbo» компании VINCI Technologies. Температурная программа: старт нагрева образца $-300{ }^{\circ} \mathrm{C}$, выдержка 3 мин, далее нагрев до $650{ }^{\circ} \mathrm{C}$ со скоростью $25{ }^{\circ} \mathrm{C} /$ мин.

Анализ экстрактов проводили методом хромато-масс-спектрометрии на приборе SCION 436 GC TQ фирмы Bruker с использованием кварцевой капиллярной колонки HP-5MS (длина 30 м, внутренний диаметр 0,25 мм, толщина пленки 0,25 мкм).

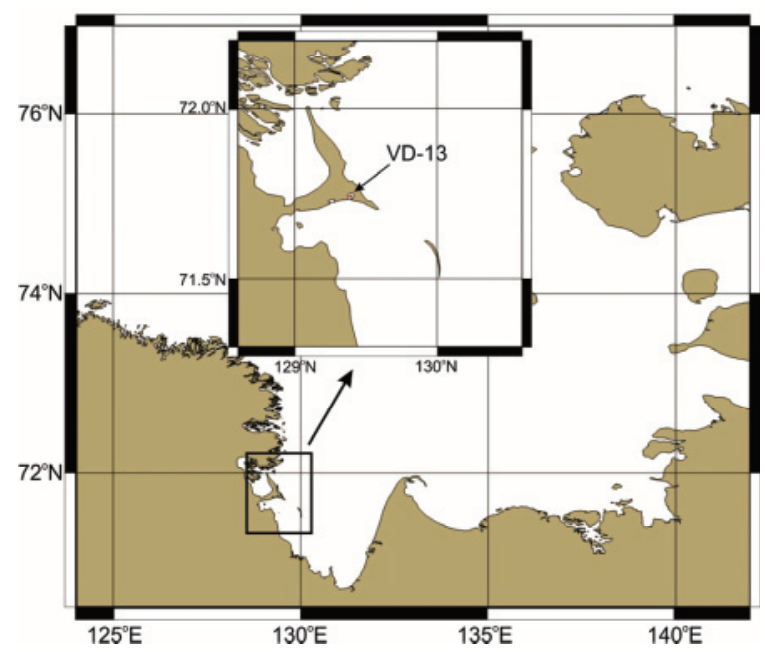

Puc. 1. Расположение скважины VD-13 (Ивашкина лагуна)

Fig. 1. Sampling location (VD-13 core, Ivashkina lagoon)

Традиционно пиролитический анализ Rock Eval применяется в нефтяной геологии для оценки генерационного потенциала нефтематеринских пород $[24,25]$. Тем не менее, в последние годы все чаще метод стал использоваться и для исследования незрелого ОВ в современных осадках и почвах [26-28]. 
Пиролиз незрелого ОВ представляет собой сложный процесс, включающий в себя несколько стадий термодеструкции отдельных его компонентов с различными химическими свойствами и термической устойчивостью, поэтому пиролитические исследования современных осадков могут быть использованы в качестве инструмента для оценки диагенетической преобразованности вещества.

\section{Результаты и обсуждение}

Как было показано ранее [29, 30], Ивашкина лагуна представляет собой термокарстовое озеро, затопленное морем в результате термоабразии при постоянном уровне моря. Геологический разрез донных отложений её котловины является типичным для подобного рода образований. Верхние примерно 1,5-2 м представлены пелитовыми озёрно-лагунными образованиями, ниже залегают собственно озерные отложения до глубины $3,7 \mathrm{~m}$ (рис. 2). В интервале 3,7-11 м озёрные отложения подстилаются преимущественно алевритовыми и песчаными таберальными образованиями - породами, которые образовались в результате протаивания отложений ледового комплекса, образовавшегося в позднем неоплейстоцене. После образования в начале голоцена первичного термокарстового озера породы ледового комплекса были уплотнены в подозерном талике и переотложены in situ, в результате чего по составу они почти не изменились, но строение их обусловлено уже процессами протаивания и уплотнения отложений, происходившими в начале голоцена. Глубже залегают песчаные отложения с включениями мелкообломочного материала и растительного детрита, подстилающие отложения ледового комплекса и имеющие, вероятно, аллювиальное происхождение и средненеоплейстоценовый возраст.

Результаты пиролитического исследования образцов керна VD-13 современных осадков приведены в таблице. Наибольшее содержание $\mathrm{C}_{\text {орг }}$ приходится на интервал 1,59-2,40 м от поверхности, сложенной преимущественно пелитовыми осадками (рис. 2). По мере углубления концентрация $\mathrm{C}_{\text {орг }}$ неравномерно уменьшается; резкий скачок значений наблюдается на глубине 5,58-6,94 м.

Пик S1 (мг/г) показывает количество летучих органических соединений, уже присутствующих в образце. Пик S2 характеризует количество углеводородов, генерируемых в результате термической деструкции керогена в процессе их нагрева до 550 ${ }^{\circ} \mathrm{C}$; при температуре Тmax отмечается максимальная скорость выхода углеводородов.

Величина водородного индекса НІ характеризует водородонасыщенность ОВ и отражает долю алифатической составляющей в структуре ОВ. P. Штейн и Р. Макдональд в своей работе отмечают, что для незрелых осадков значения параметра НI маркируют генетическую принадлежность ОВ так же, как для зрелой органики данный параметр указывает на тип керогена [31, 32]. Так, значения HI $<100$ мг г вкупе с высоким кислородным индек- сом ОI свидетельствуют о преимущественно терригенном глубоко окисленном ОВ (гумусовое вещество, кероген III типа), в то время как высокие значения (от 300 до 800) типичны для морского генезиса и преобладания восстановительных условий (сапропелевое вещество, кероген I и II типа) (рис. 3).

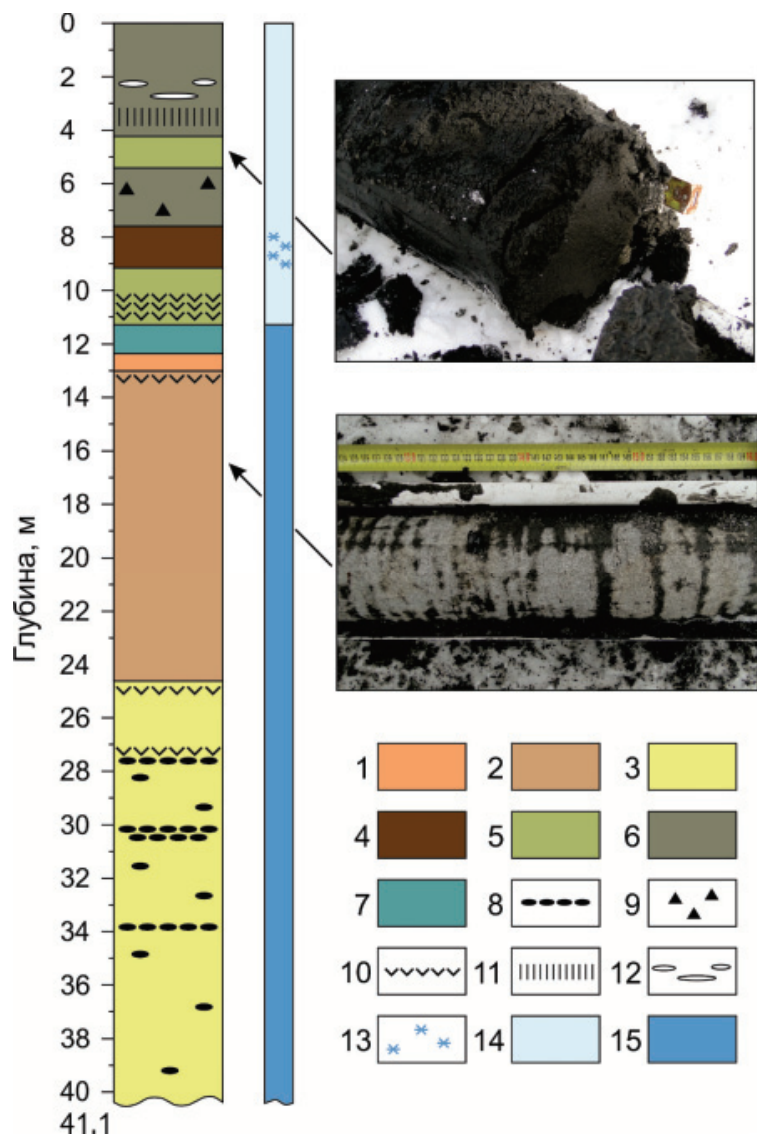

Puc. 2. Литологическая колонка по керну буровой скважины VD-13 (по данным лаборатории арктических исследований ТОИ ДВО РАН ): 1 - крупнозернистый песок; 2 - среднезернистый песок; 3 - мелкозернистый песок; 4 - алеврит песчаный; 5 - алеврит пелитовый; 6 - пелит; 7 - миктит; 8 - гравийно-галечные прослои; 9 - единичная дресва; 10 - растительные остатки. Текстура отложений: 11 - вертикальная полосчатость, 12 - линзовидная, 13 со шлирами льда. Криогенное состояние отложений: 14 охлажденное; 15 - мерзлое

Fig. 2. Lithological column for VD-13 core (data of POI FEB RAS Arctic Research Laboratory): 1 is the coarse-grained sand; 2 is the medium-grained sand; 3 is the fine-grained sand; 4 is the sandy silt; 5 is the pelitic aleurite; 6 is the pelite; 7 is the myctitis; 8 is the gravel-pebble interlayers; 9 is the debris; 10 are the plant remains. Sediments texture: 11 - vertical banding; 12 - lenticular; 13 - with ice schlieren. Sediments cryogenic state: 14 - cooled; 15 - frozen

Пик S1 (мг/г) показывает количество летучих органических соединений, уже присутствующих в образце. Пик S2 характеризует количество углеводородов, генерируемых в результате термической деструкции керогена в процессе их нагрева до $550{ }^{\circ} \mathrm{C}$; при температуре Tmax отмечается максимальная скорость выхода углеводородов. 
таблица. Результаты пиролитических и хромато-масс-спектрометрических исследований образцов

Table. Rock-Eval and GC-MS analysis data

\begin{tabular}{|c|c|c|c|c|c|c|c|c|c|c|c|}
\hline \multirow{2}{*}{$\begin{array}{l}\text { Глубина отбора, см } \\
\text { Sampling depth, cm }\end{array}$} & S1 & S2 & \multirow{2}{*}{$\mathrm{T}_{\max },{ }^{\circ} \mathrm{C}$} & $\mathrm{HI}$ & OI & \multirow{2}{*}{$\begin{array}{c}\text { TOC, } \% \text { mac. } \\
\% \text { wt }\end{array}$} & \multirow{2}{*}{ CPI } & \multirow{2}{*}{$\mathrm{OEP}_{17}$} & \multirow{2}{*}{$\mathrm{OEP}_{19}$} & \multirow{2}{*}{$\begin{array}{l}\mathrm{C}_{14}-\mathrm{C}_{19} / \\
\mathrm{C}_{14}-\mathrm{C}_{35}\end{array}$} & \multirow{2}{*}{$\begin{array}{l}\mathrm{C}_{15}+\mathrm{C}_{17}+\mathrm{C}_{19} / \\
\mathrm{C}_{27}+\mathrm{C}_{29}+\mathrm{C}_{31}\end{array}$} \\
\hline & \multicolumn{2}{|c|}{$\mathrm{Mг} / \mathrm{\Gamma} / \mathrm{mg} / \mathrm{g}$} & & \multicolumn{2}{|c|}{ мг $/ \mathrm{\Gamma} / \mathrm{mg} / \mathrm{g}$} & & & & & & \\
\hline 36 & 0,20 & 2,17 & 423 & 108 & 167 & 2,00 & 4,65 & 1,22 & 1,52 & 0,20 & 0,30 \\
\hline 159 & 0,21 & 2,52 & 424 & 108 & 175 & 2,33 & 5,99 & 1,12 & 1,44 & 0,13 & 0,16 \\
\hline 240 & 0,22 & 3,43 & 429 & 154 & 160 & 2,23 & 4,18 & 1,08 & 1,18 & 0,12 & 0,16 \\
\hline 390 & 0,12 & 2,78 & 424 & 150 & 193 & 1,85 & 4,41 & 1,25 & 1,18 & 0,15 & 0,20 \\
\hline 558 & 0,06 & 1,33 & 421 & 100 & 302 & 1,33 & 3,84 & 1,09 & 0,86 & 0,09 & 0,12 \\
\hline 694 & 0,00 & 0,04 & - & 10 & 349 & 0,41 & - & - & - & - & - \\
\hline 827 & 0,00 & 0,15 & - & 28 & 283 & 0,54 & - & - & - & - & - \\
\hline 940 & 0,00 & 0,06 & - & 20 & 450 & 0,30 & - & - & - & - & - \\
\hline 1023 & 0,00 & 0,11 & - & 16 & 639 & 0,67 & - & - & - & - & - \\
\hline 1126 & 0,00 & 0,06 & - & 11 & 156 & 0,55 & - & - & - & - & - \\
\hline 1228 & 0,06 & 0,57 & - & 57 & 151 & 0,96 & - & - & - & - & - \\
\hline 1290 & 0,00 & 0,00 & - & 0 & 433 & 0,09 & - & - & - & - & - \\
\hline 1405 & 0,00 & 0,09 & - & 24 & 145 & 0,38 & - & - & - & - & - \\
\hline 1524 & 0,00 & 0,00 & - & 0 & 353 & 0,15 & - & - & - & - & - \\
\hline 1624 & 0,00 & 0,00 & - & 0 & 325 & 0,08 & - & - & - & - & - \\
\hline 1710 & 0,00 & 0,00 & - & 0 & 455 & 0,11 & - & - & - & - & - \\
\hline 1790 & 0,01 & 0,00 & - & 0 & 468 & 0,19 & - & - & - & - & - \\
\hline
\end{tabular}

Примечание: TOC - total organic carbon (количество органического углерода), \% мас.; $S 1$ - количество летучих (300 ${ }^{\circ} \mathrm{C}$ ) органических соединений, мг/г породы; S2 - количество летучих продуктов деструкиии органического вещества, мг/г породы; НI - водородный индекс

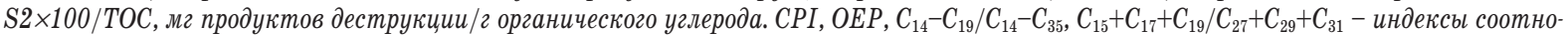
шения четных и нечетных н-алканов

Note: TOC - total organic carbon (amount of organic carbon), \% by weight; $\mathrm{S} 1$ - amount of volatile ( $300^{\circ} \mathrm{C}$ ) organic compounds, $\mathrm{mg} / \mathrm{g}$ of rock; $S 2$ - amount of volatile organic matter degradation products, $\mathrm{mg} / \mathrm{g}$ of rock; $\mathrm{HI}$ - hydrogen index $\mathrm{S} 2 \times 100 / \mathrm{TOC}$, $\mathrm{mg}$ of degradation products/g of organic carbon. CPI, OEP, $C_{14}-C_{19} / C_{14}-C_{35}$, $\left[C_{15}+C_{17}+C_{19} / C_{27}+C_{29}+C_{31}-\right.$ indices of odd and even n-alkanes interrelations

Величина водородного индекса НI характеризует водородонасыщенность ОВ и отражает долю алифатической составляющей в структуре ОВ. Р. Штейн и Р. Макдональд в своей работе отмечают, что для незрелых осадков значения параметра НI маркируют генетическую принадлежность ОВ так же, как для зрелой органики данный параметр указывает на тип керогена $[31,32]$. Так, значения $\mathrm{HI}<100$ мг/г вкупе с высоким кислородным индексом ОI свидетельствуют о преимущественно терригенном глубоко окисленном ОВ (гумусовое вещество, кероген III типа), в то время как высокие значения (от 300 до 800) типичны для морского генезиса и преобладания восстановительных условий (сапропелевое вещество, кероген I и II типа) (рис. 3).

Для ОВ современных осадков Ттах, как правило, составляет $<425{ }^{\circ} \mathrm{C}$. Сопоставление значений Tmax и индекса НI также позволяет получить информацию о составе ОВ.

Увеличение водородного индекса указывает на более восстановительные условия осадконакопления. К наиболее окисленным осадкам следует отнести нижние интервалы, которые с учетом низкого содержания $\mathrm{C}_{\text {орг }}$, могут свидетельствовать об активном взаимодействии осадков с насыщенными кислородом водами. Соотнесение Тmax и НI указывает на смешение источников $\mathrm{C}_{\text {орг }}$ с ожидаемым значительным вкладом морской органики в верхних горизонтах разреза.

Повышенное содержание ТОС и НI в верхних горизонтах разреза свидетельствует о более тонком гранулометрическом составе отложений и накоплении их в восстановительных условиях. Это позволяет считать, что их формирование происходило в озёрных и озёрно-лагунных условиях. Ниже по разрезу, там, где увеличивается кислородный индекс и уменьшается содержание $\mathrm{C}_{\text {орг }}$, эти параметры характеризуют древние аллювиальные отложения. Неравномерное изменение этих характеристик с глубиной отражает, по всей видимости, неравномерное распределение ОВ в слоистых аллювиальных толщах.

В данном интервале также отмечаются скачки значений HI и OI, что указывает на резкую смену обстановки осадконакопления с восстановительной на окислительную или на вклад аллохтонного глубоко окисленного материала (интервалы $12,28-12,90$ и 10,23-11,26 м) (рис. 4, б, в). Однако, учитывая в целом низкие содержания $\mathrm{C}_{\text {орг }}$ и практически полное отсутствие идентифицированного пика S1, необходимо принимать во внимание возможную большую погрешность при расчете индексов НI и ОI.

Для исследования методом хромато-масс-спектрометрии были выбраны пять образцов верхней части разреза в интервале 0,36-5,58 м, так как лишь они содержали в своем составе летучие органические соединения (пик S1) в достаточном для анализа количестве. Значения параметров S1 и S2 для указанного интервала устойчиво коррелируют с общим количеством органического углерода в осадке (ТОС) (рис. 5, $a$, б). 

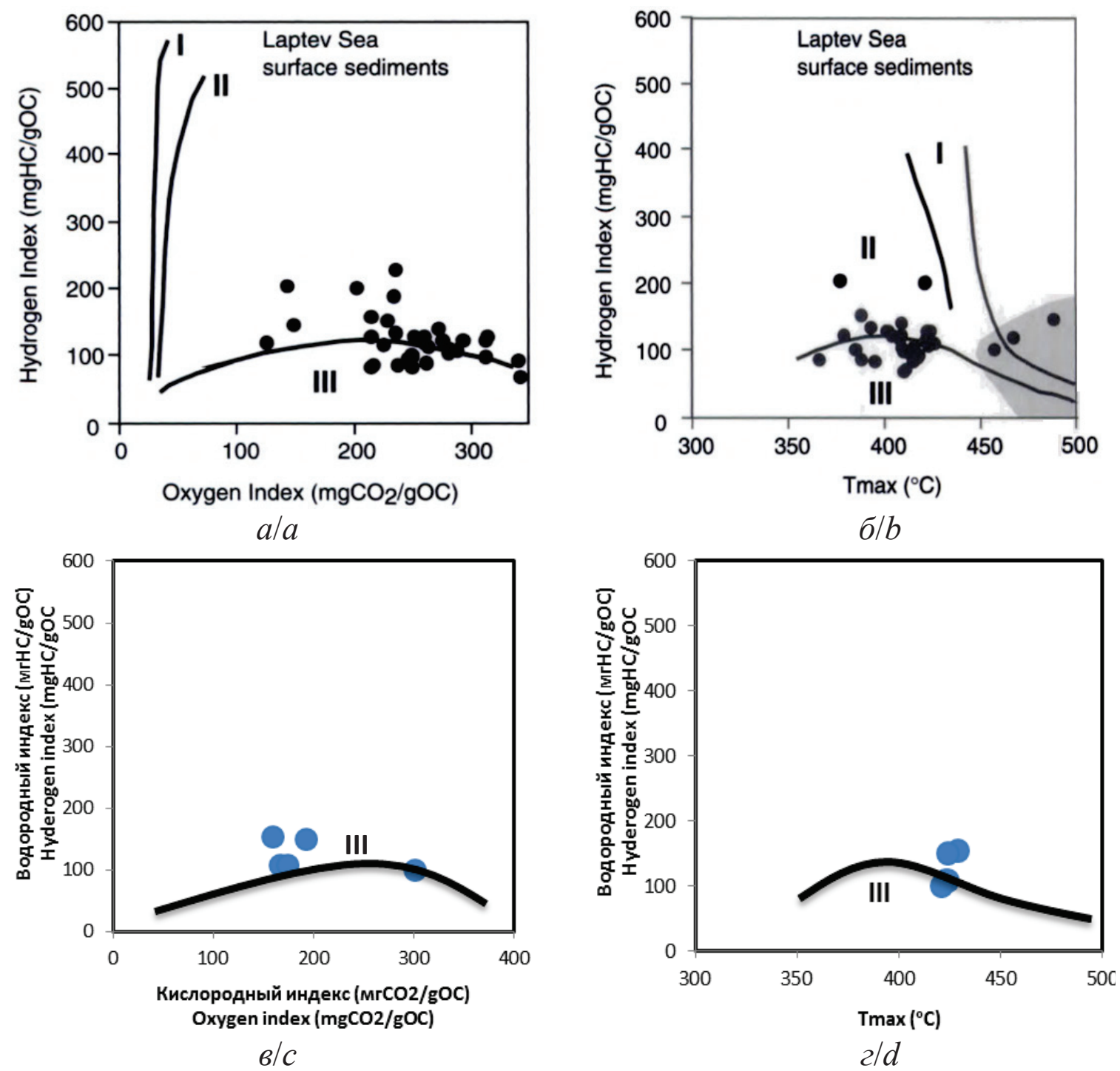

Pис. 3. Результаты пиролитического анализа образиов донных осадков (Rock Eval): зависимость водородного индекса НI от кислородного индекса ОI (а, в), от Ттах (б, г). а, б) данные, опубликованные у Б. Тиссо и Д. Вельте [31]; в, г) данные авторов. I и II- кероген I и II типа (сапропелевое вещество), III - кероген III типа (гумусовое вещество)

Fig. 3. Pyrolisis data (Rock Eval analysis): correlation between hydrogen index (HI) and oxygen index (OI) (a,c), and Tmax (b,d). a,b) the data published by [31]; $c, d$ ) the data obatined by authors. I and II - kerogen type I and II (sapropel organic matter), III - kerogen type III (humic organic matter)

На рис. 6 приведены распределения насыщенных углеводородов (УВ) для указанного интервала. Несомненно, доминирующий вклад в органическую компоненту внес экспорт наземного материала: в распределении н-алканов преобладают гомологи $\mathrm{C}_{27}, \mathrm{C}_{29}, \mathrm{C}_{31}$ - маркеры высшей наземной растительности. На преимущественно терригенный генезис ОВ исследованных осадков также указывают низкие значения параметров соотношения низкомолекулярных и высокомолекулярных гомологов $\left[\mathrm{C}_{14}-\mathrm{C}_{19} / \mathrm{C}_{14}-\mathrm{C}_{35}\right],\left[\mathrm{C}_{15}+\mathrm{C}_{17}+\mathrm{C}_{19} / \mathrm{C}_{27}+\mathrm{C}_{29}+\mathrm{C}_{31}\right]$, а также индексы соотношения четных и нечетных н-алканов CPI, OEP17, OEP19 (таблица). Индекс нечетности CPI практически во всех образцах имеет высокие значения (>>2), что указывает на сла- бую диагенетическую преобразованность и, соответственно, маркирует постоянное поступление в осадки свежего органического материала неморского происхождения, что наблюдается во всей мелководной зоне MBA и в наше время $[9,14]$.

Необходимо отметить, что в данном районе (скважина VD-13) документировано интенсивное газопроявление. Вопрос о генезисе газового флюида был подробно рассмотрен в работе [33]. На основе уникальных данных тройного изотопного анализа $\left(\delta^{13} \mathrm{C}_{\text {сн4 }}{ }^{14} \mathrm{C}_{\text {сн4 }}, \delta \mathrm{D}\right)$ авторы отметили ключевую роль ацетокластического метаногенеза, причем в качестве субстрата мог быть использован плейстоценовый углерод, ремобилизованный из протаивающей мерзлоты. 

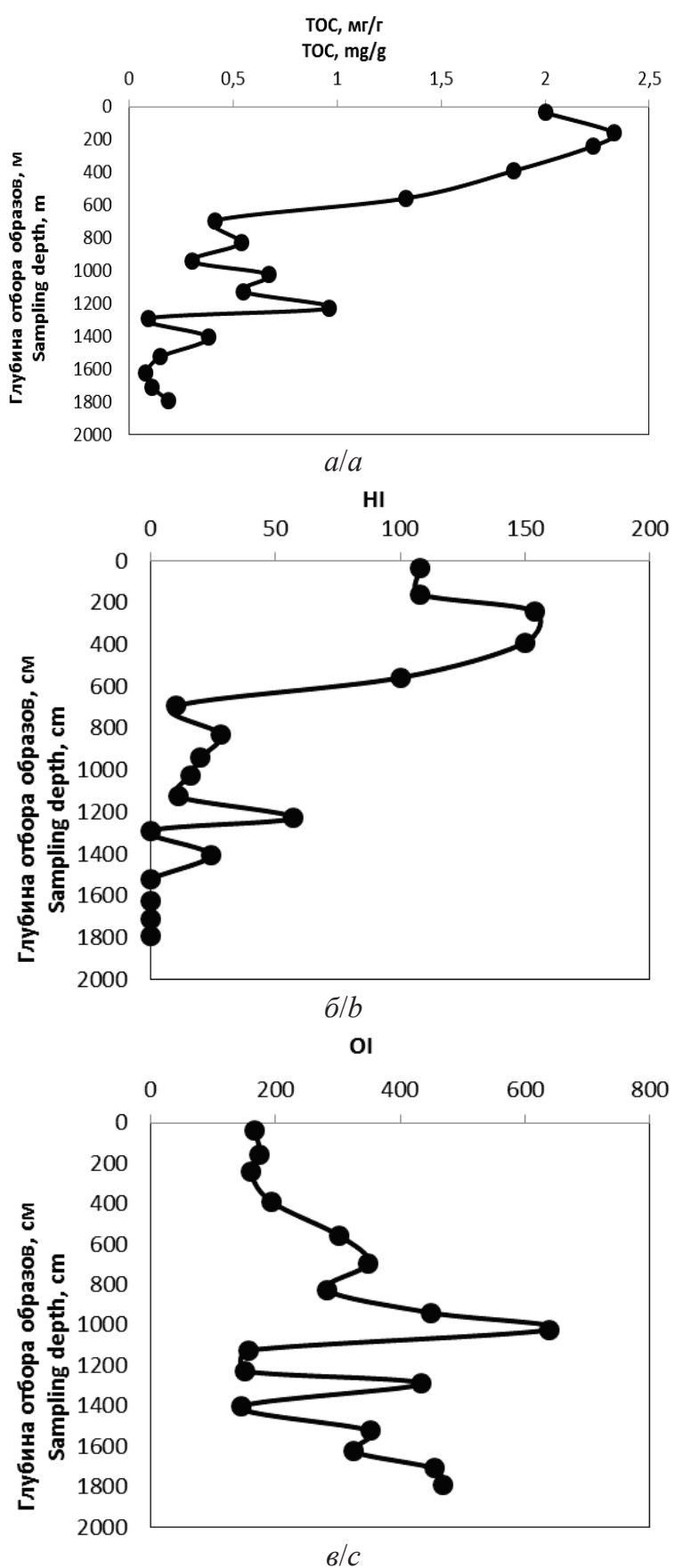

Pис. 4. Зависилость ТОС (а), водородного (НI) (б) и кислородного (ОI) (в) индексов от глубины (см.)

Fig. 4. TOC (a), hydrogen (HI) (b) and oxygen (OI) (c) indices vs. depth $(\mathrm{cm})$

С целью выявления миграционной составляющей наиболее информативной можно считать УВ фракцию $\mathrm{C}_{10}-\mathrm{C}_{14}$, как характеризующуюся наименьшим вкладом УВ современного генезиса в случае ее наличия в поверхностных донных осадках. Природа низкомолекулярных четных н-алканов не так однозначна. Присутствие четных гомологов указывает на автохтонный биогенный вклад свежесинтезированного ОВ и трансформацию высокомолекулярных н-алканов в результате микробиаль- ной деятельности. При этом очевидно, что с увеличением глубины залегания осадка вклад низкомолекулярных гомологов, характерных для гидробионтов и планктоногенного ОВ, уменьшается. Не исключен возможный точечный вклад нафтидогенных углеводородов, обеспечивающийся газовыводящими потоками, зафиксированными в исследуемом районе [12]. Необходимо еще раз отметить, что достоверное установление типа биопродуцента может производиться только при комплексной интерпретации нескольких геохимических параметров.

В связи с отсутствием в образцах достоверно детектируемых пристана и фитана для керна VD-13 не использовался расчет изопреноидных коэффициентов.
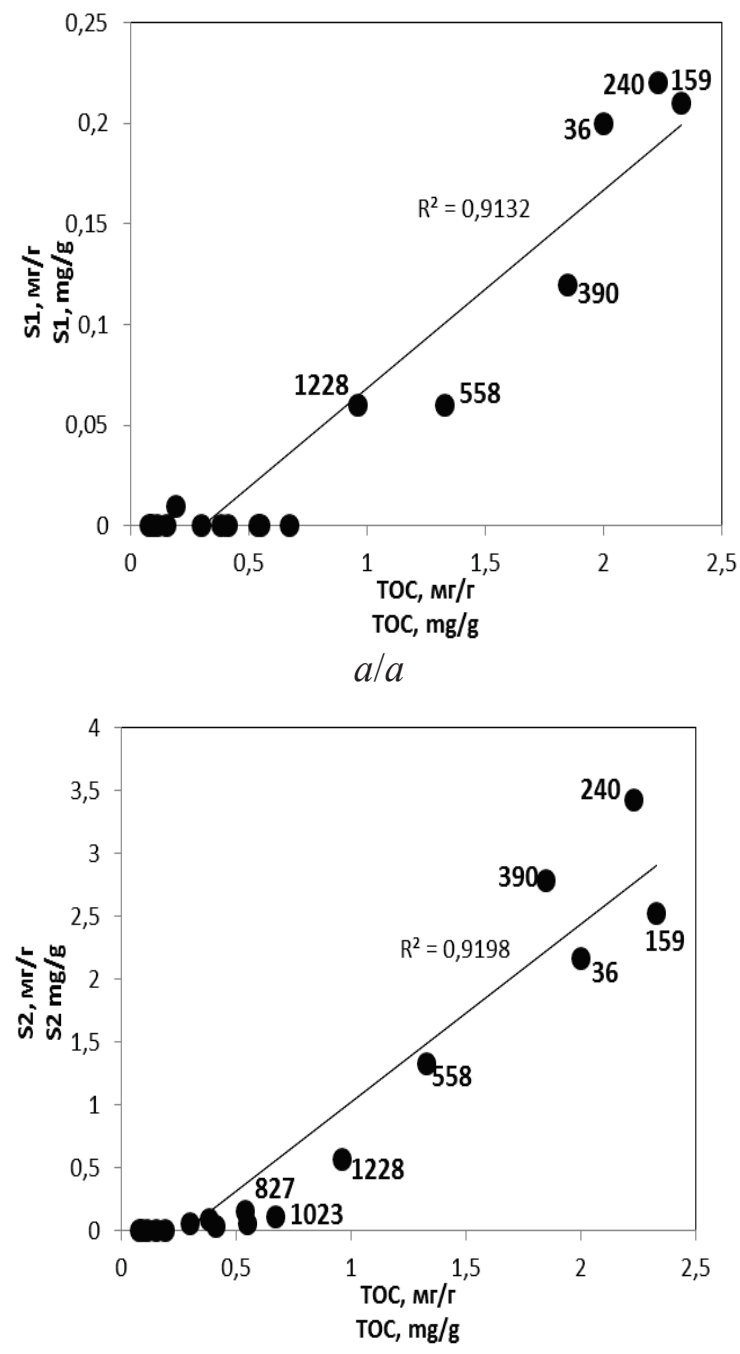

$\sigma / b$

Puc.5. Взаилосвязь параметров ТOC и S1 (а), S2 (б) (примечание к таблице). Черными точкали обозначены значения для отмеченных глубин отбора (см) при $S 1>0,05 \mathrm{mz} / 2$ (a), $S 2>0,1 \mathrm{mz} / 2$ (б)

Fig. 5. Correlation of TOC and S1 (a), S2 (b) parameters (Note to Table). Black dots indicate defined values for relevant sampling depths (cm) when $S 1>0,05 \mathrm{mg} / \mathrm{g}(\mathrm{a}), S 2>0,1 \mathrm{mg} / \mathrm{g}(\mathrm{b})$ 
VD-13 36

15

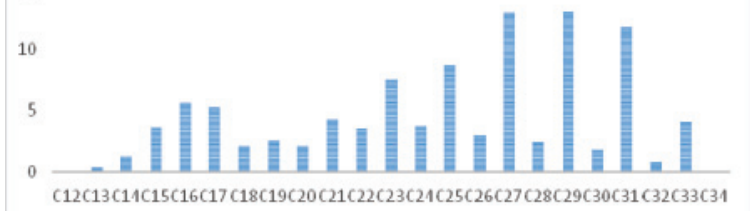

VD-13 159

20

15

10

5

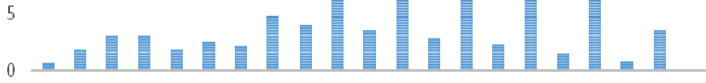

C14C15 C16 C17 C18C19 C20C21 C22 C23 C24C25 C26 C27 C28C29 C30 C31 C32 C33C34

\section{VD-13 240}

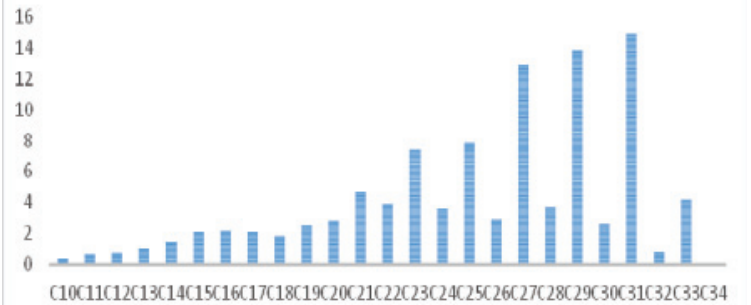

\section{Выводы}

В изученном разрезе отложений, отобранных в пределах термокарстовой лагуны Быковского полуострова, отмечается приуроченность повышенного содержания органического углерода к пелитовой фракции осадков. Проведенные исследования молекулярного состава в разрезе указывают на повсеместно определяющий вклад высшей наземной растительности в формирование органической компоненты. Распределение н-алканов характеризуется доминированием высокомолекулярных нечетных гомологов. Результаты пиролитического анализа образцов указывают на резкую изменчивость содержания $\mathrm{C}_{\text {орг }}$ и летучих органических соединений с глубиной. Это может быть связано с первоначальной неоднородностью распределения ОВ в разрезе. На следующих этапах исследования планируется расширить реализацию изложенного в

\section{СПИСОК ЛИТЕРАТУРЫ}

1. Extensive methane venting to the atmosphere from sediments of the East Siberian Arctic Shelf / N. Shakhova, I. Semiletov, A. Salyuk, V. Yusupov, D. Kosmach, 0. Gustafsson. Science. - 2010. V. 327. - P. 1246-1250.

2. Жигарев Л.А. Океаническая криолитозона. - М.: Изд-во «Недра», 1997. - 320 c.

3. Романовский Н.Н., Хуббертен Г.В. Формирование и эволюция криолитозоны шельфа и приморских низменностей (на приме-
VD-13 390

20

15

10

5

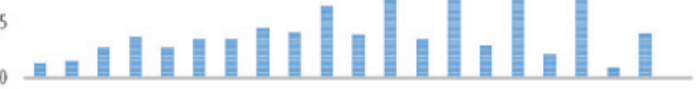

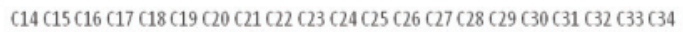

VD-13 558

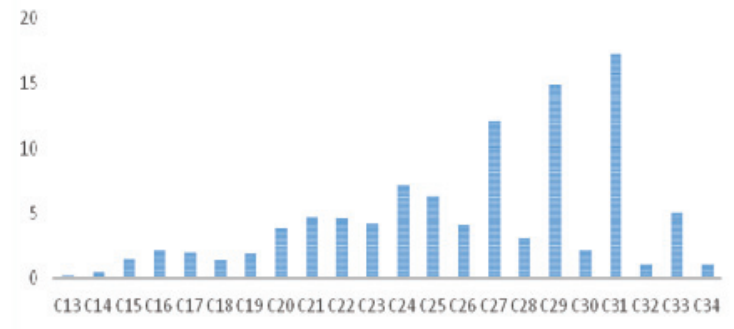

Puc.6. Относительное молекулярно-массовое распределение налканов в экстрактах образиов керна VD-13 N, где $N$ глубина (см). По оси ординат отмечены процентное содержание соответствующих голологов (ось абсиисс)

Fig. 6. Relative molecular-mass distribution of n-alkanes in VD-13 core samples (defined as "VD-13 N" sample, where $N$ is the sampling depth, $\mathrm{cm}$ ). Vertical axis indicates percentage of relevant n-alkanes homologues (horizontal axis)

данной работе подхода на весь шельф МВА, в том числе для современных поверхностных осадков.

Работа выполнена при поддержке РНФ (иель и структура исследования были определены в рамках проекта № 15-17-200-32-П; рук. Н.Е. Шахова).Е.В.Гершелис благодарит за поддержку части аналитических исследований РФФИ: ХМС анализ экстрактов и интерпретация полученных результатов были выполнены при поддержке проекта № 18-35-00572 мол_а. Исследования (пробоподготовка и гранулометрический анализ) также выполнялись при частичной финансовой поддержке РФФИ (проект № 18-05-00559) и Програмль «Дальний Восток» (грант № 18-1-008).

Авторы также благодарят научный коллектив лаборатории арктических исследований Тихоокеанского океанологического института им.В.И. Ильичева Дальневосточного отделения РАН за помощь при подготовке работы и уважаемого рецензента за ценные замечания и рекомендации.

ре региона моря Лаптевых) // Известия Российской Академии наук. Серия географическая. - 2001. - № 3. - С. 15-28.

4. Фартышев А.И. Особенности прибрежно-шельфовой криолитозоны моря Лаптевых. - Новосибирск: Наука, 1993. - 136 с.

5. Climate change and the permafrost carbon feedback / E.A.G. Schuur, A.D. McGuire, C. Schaedal, G. Grosse, J.W. Harden, D.J. Hayes, G. Hugelius, C.D. Koven, P. Kuhry, D.M. Lawrence, S.M. Natali, D. Olefeldt, V.E. Romanovsky, K. Schaefer, M.R. Turetsky, C.C. Treat, J.E. Vonk // Nature. 2015. - V. 520. - P. 171-179. 
6. Vonk J.E., Gustafsson 0. Permafrost-carbon complexities // Nature Geoscience. - 2013. - V. 6 (9). - P. 675-676.

7. Soil organic carbon pools in the northern circumpolar permafrost region / C. Tarnocai, J.G. Canadell, E.A.G. Schuur, P. Kuhry, G. Mazhitova, S. Zimov // Global Biogeochemical Cycles. 2009. - V. 23. - GB2023.

8. Vetrov A.A., Romankevich E.A. Carbon Cycle in the Russian Arctic Seas. - Berlin: Springer, 2004. - 331 p.

9. Accelerating rates of Arctic carbon cycling revealed by long-term atmospheric $\mathrm{CO}_{2}$ measurements / S. Jeong, A. Bloom, D. Schimel, C. Sweeney, N. C. Parazoo, D. Medvigy, G. Schaepman-Strub, C. Zheng, C.R. Schwalm, D.N. Huntzinger, A.M. Michalak, C.E. Miller // Science Advances. - 2018. - V. 4. - № 7. - eaao1167.

10. Sensitivity of the carbon cycle in the Arctic to climate change/ A.D. McGuire, L.G. Anderson, T.R. Christensen, S. Dallimore, L. Guo, D.J. Hayes, M. Heimann, T.D. Lorenson, R.W. Macdonald, N. Roulet // Ecological Monographs. - 2009. - V. 79. № 4. - P. 523-555.

11. The East Siberian Arctic Shelf: towards further assessment of permafrost-related methane fluxes and role of sea ice / N. Shakhova, I. Semiletov, V. Sergienko, L. Lobkovsky, V. Yusupov, A. Salyuk, A. Salomatin, D. Chernykh, D. Kosmach, G. Panteleev, D. Nicolsky, V. Samarkin, S. Joye, A. Charkin, O. Dudarev, A. Meluzov, Ö. Gustafsson // Philosophical Transactions of the Royal Society A. - 2015. - V. 373. - 20140451.

12. Friedlingstein P. Carbon cycle feedbacks and future climate change // Philosophical Transactions of the Royal Society A. - 2015. V. 373. -20140421.

13. Matrix association effects on hydrodynamic sorting and degradation of terrestrial organic matter during cross-shelf transport in the Laptev and East Siberian shelf seas / T. Tesi, I. Semiletov, 0. Dudarev, A. Andersson, Ö. Gustafsson // Journal of Geophysical Research. Biogeosciences. - 2016. - V. 121. - P. 731-752.

14. Pugach S.P., Pipko I.I. Dynamics of colored dissolved matter on the East Siberian sea shelf // Doklady Earth Sciences. - 2013. V. 448. - № 1. - P. 153-156.

15. Acidification of East Siberian Arctic Shelf waters through addition of freshwater and terrestrial carbon / I. Semiletov, I. Pipko, Ö. Gustafsson, L.G. Anderson, V. Sergienko, S. Pugach, 0. Dudarev, A. Charkin, A. Gukov, L. Bröder, A. Andersson, E. Spivak, N. Shakhova // Nature Geoscience. - 2016. - V. 9. - P. 361-365.

16. Current rates and mechanisms of subsea permafrost degradation in the East Siberian Arctic Shelf / N. Shakhova, I. Semiletov, 0. Gustafsson, V. Sergienko, L. Lobkovsky, 0. Dudarev, V. Tumskoy, M. Grigoriev, A. Mazurov, A. Salyuk, R. Ananiev, A. Koshurnikov, D. Kosmach, A. Charkin, N. Dmitrevsky, V. Karnaukh, A. Gunar, A. Meluzov, D. Chernykh // Nature Communications. -2017 . - V. 8. -15872.

17. Contribution of Working Groups I, II and III to the Fourth Assessment Report of the Intergovernmental Panel on Climate Change / Eds. R.K. Pachauri, A. Reisinger // IPCC, 2007: Climate Change 2007: Synthesis Report. - 2007. - 104 p. URL: https://www. ipcc.ch/site/assets/uploads/2018/02/ar4_syr_full_report.pdf (дата обращения 06.10.2018).

18. Kattsov V.M., Källén E. Arctic Climate Impact Assessment (ACIA). Impacts of a warming arctic. Ch. 4: Future climate change: mode- ling and scenarios. - Cambridge: Cambridge University Press, 2005. - P. 99-150.

19. Problems of arctic shelf research: the experience from integrated geologic and geochemical studies in the Laptev sea / A.S. Ulyantsev, L.I. Lobkovsky, A.V. Zhavoronkov, E.A. Romankevich // Oceanology. - 2015. - V. 55. - № 6. - P. 919-925.

20. Vetrov A.A., Romankevich E.A. Interannual variability of the primary production and organic carbon fluxes in the Arctic seas of Russia // Oceanology. - 2008. - V. 48. - № 3. - P. 340-348.

21. Тумской В.Е. Термокарст и его роль в развитии региона моря Лаптевых в позднем плейстоцене и голоцене: автореф. дис. ... канд. геол.-минерал. наук. - М., 2002. - 26 с.

22. Лихт Ф.Р. Структура осадков и фации Японского моря. - Владивосток: Изд-во ДВНЦ АН СССР, 1983. - 283 с.

23. Peters K.E., Walters C.C., Moldowan J.M. The Biomarker Guide. $2^{\text {nd }}$ ed. P. I. Biomarkers and Isotopes in the Environmental and Human History. - Cambridge: Cambridge University Press, 2005. $-387 \mathrm{p}$.

24. Peters K.E. Guidelines for evaluating petroleum source rock using programmed pyrolysis // American Association of Petroleum Geologists. - 1986. - V. 70. - P. 318-329.

25. Soil organic matter (SOM) characterization by Rock-Eval pyrolysis: scope and limitation / J.-R. Disnar, B. Guillet, D. Keravis, C. Di Giovanni, D. Sebag // Organic Geochemistry. - 2003. V. 34 . - P. 327-343.

26. Меленевский В.Н., Леонова Г.А., Конышев А.С. Результаты исследования органического вещества современных осадков озера Белое (Западная Сибирь) по данным пиролитических методов // Геология и геофизика. - 2011. - Т. 52. - № 6. C. $751-762$.

27. Monitoring organic matter dynamics in soil profiles by 'RockEval pyrolysis': bulk characterization and quantification of degradation / D. Sebag, J.-R. Disnar, B. Guillet, C. Di Giovanni, E.P. Verrecchia, A. Durand // European Journal of Soil Science. 2006. - V. 57. - P. 344-355.

28. Термокарст и его роль в формировании прибрежной зоны шельфа моря Лаптевых / Н.Н. Романовский, А.В. Гаврилов, В.Е. Тумской, А.Л. Холодов // Криосфера Земли. - 1999. T. III. - № 3. - C. 79-91.

29. Чеверев В.Г., Видяпин И.Ю., Тумской В.Е. Состав и свойства отложений термокарстовых лагун Быковского полуострова // Криосфера Земли. - 2007. - Т. XI. - № 3. - С. 44-50.

30. Stein R., Macdonald R.W. Organic carbon budget: Arctic Ocean vs. Global Ocean / The organic carbon cycle in the Arctic Ocean / Eds. R. Stein, R.W. Macdonald. - Berlin: Springer-Verlag, 2004. - P. 315-322.

31. Тиссо Б., Вельте Д. Образование и распространение нефти. М.: Мир, 1981. $-502 \mathrm{c.}$

32. The origin of methane in the East Siberian Arctic Shelf unraveled with triple isotope analysis / C.J. Sapart, N. Shakhova, I. Semiletov, J. Jansen, S. Szidat, D. Kosmach, 0. Dudarev, C. van der Veen, M. Egger, V. Sergienko, A. Salyuk, V. Tumskoy, J.L. Tison, T. Rockmann // Biogeosciences. - 2017. - V. 14. - № 9. P. 2283-2292. 


\section{Информация об авторах}

Гершелис (Панова) E.B., ассистент отделения геологии Инженерной школы природных ресурсов Национального исследовательского Томского политехнического университета.

Гончаров И.В., доктор геолого-минералогических наук, профессор отделения геологии Инженерной школы природных ресурсов Национального исследовательского Томского политехнического университета.

Дударев О.В., доктор геолого-минералогических наук, ведущий научный сотрудник Лаборатории арктических исследований Тихоокеанского океанологического института им. В.И. Ильичева Дальневосточного отделения Российской Академии наук; научный сотрудник Международной научно-образовательной лаборатории изучения углерода арктических морей Инженерной школы природных ресурсов Национального исследовательского Томского политехнического университета.

Рубан A.C., кандидат геолого-минералогических наук, ассистент отделения геологии Инженерной школы природных ресурсов Национального исследовательского Томского политехнического университета.

Перевертайло T.Г., кандидат геолого-минералогических наук, доцент отделения геологии Инженерной школы природных ресурсов Национального исследовательского Томского политехнического университета.

Щербакова К.П., инженер Лаборатории арктических исследований Тихоокеанского океанологического института им. В.И. Ильичева Дальневосточного отделения Российской Академии наук.

Шахова H.E., доктор геолого-минералогических наук, ведущий научный сотрудник Международной научнообразовательной лаборатории изучения углерода арктических морей Инженерной школы природных ресурсов Национального исследовательского Томского политехнического университета.

Семилетов И.П., доктор географических наук, член-корреспондент Российской Академии наук, заведующий Лабораторией арктических исследований Тихоокеанского океанологического института им. В.И. Ильичева Дальневосточного отделения Российской Академии наук; профессор Международной научно-образовательной лаборатории изучения углерода арктических морей Инженерной школы природных ресурсов Национального исследовательского Томского политехнического университета. 
UDC: 550.4:551.3:552.14

\section{GEOCHEMICAL CHARACTERISTICS OF ORGANIC MATTER IN BOTTOM SEDIMENTS IN IVASHKINA LAGOON (BYKOVSKY PENINSULA, LAPTEV SEA)}

Elena V. Gershelis (Panova)',

elenapanova@tpu.ru

Ivan V. Goncharov',

GoncharovIV@nipineft.ru

Oleg V. Dudarev ${ }^{2,1}$,

dudarev@poi.dvo.ru

Alexey S. Ruban', ruban@tpu.ru

Tatyana G. Perevertaylo', ptg@tpu.ru

Kseniya P. Shcherbakova ${ }^{2}$, ksushok7@mail.ru

Natalia E. Shakhova', shahova@tpu.ru

Igor P. Semiletov ${ }^{2,1}$, ipsemiletov@alaska.edu

1 National Research Tomsk Polytechnic University, 30, Lenin Avenue, Tomsk, 634050, Russia.

2 Pacific Oceanological Institute, Russian Academy of Sciences, 43, Baltiyskaya street, Vladivostok, 690041, Russia

Studying Arctic biogeochemical ecosystem with various methods and approaches is of vital importance to further predict future global climate changes. Organic matter of modern bottom sediments, which accumulates heterogeneous signals of various processes of carbon transport and transformation, acts as the unique indicator of initial depositional environment of sediment and its diagenetic history. Using high-precision geochemical instruments allows us to obtain important information on potential input of both allochthonous and autochthonous components to organic matter, and thus to further promote understanding of the modern Arctic carbon cycle.

The aim of the research is to study the lithological and organo-geochemical features of the sediments accumulated in the specific lagoon conditions of the coastal part of the Laptev Sea (Ivashkina Lagoon, Bykovsky Peninsula).

Materials and methods. Precipitation in the area of the Lena river delta was selected as an object of the study. To assess the variability of molecular composition of organic matter in accumulation of sediments, the 18-meter interval of the VD-13 well, drilled in the central part of the Ivashkina lagoon during the 2013 spring Arctic expedition, was investigated. For the samples, their granulometric characteristics were determined, and pyrolytic and chromatography-mass spectrometric studies were conducted as well. It is shown that the increased content of organic carbon in the section is confined to the pelitic fraction of sediments. The distribution of $n$-alkanes is characterized by the dominance of high molecular weight odd homologues, which indicates the ubiquitous contribution of higher terrestrial vegetation to formation of organic matter accumulated in sediments. However, the contribution of the potentially migratory organic component is not excluded, since the presence of a low molecular weight fraction of $n$-alkanes is noted for a number of samples. The results of the pyrolytic analysis of the samples indicate a sharp variability in the content of $C_{\text {org }}$ and volatile organic compounds with depth.

Key words:

East-Siberian shelf, bottom sediments, organic carbon, pyrolysis, modern sediments.

The research was supported by the RSF (project no. 15-17-200-32-П; project manager N.E. Shakhova). E.V. Gershelis appreciates support of the research by the RFBR (project no. 18-35-00572 mol a). The analytic investigations were partially financially supported by the RFBR (project no. 18-05-00559) and the Program «Far East» (grant no. 18-1-008).

The authors thank the research team of the POI DVO RAS Arctic research laboratory for the assistance with performing this study. The authors also thank the reviewer for valuable comments and recommendations. 


\section{REFERENCES}

1. Shakhova N., Semiletov I., Salyuk A., Yusupov V., Kosmach D., Gustafsson 0. Ex tensive methane venting to the atmosphere from sediments of the East Siberian Arctic Shelf. Science, 2010a, vol. 327 , pp. 1246-1250.

2. Zhigarev L.A. Okeanicheskaya kriolitozona [Oceanic Cryolithozone]. Moscow, Moscow State University Publ., 1997. 320 p.

3. Romanovskiy N.N., Hubberten G.V. Formirovanie i evolyutsiya kriolitozony shelfa i primorskikh nizmennostey (na primere regiona morya Laptevykh) [Formation and evolution of shelf cryolithozone and marine plains (Laptev Sea)]. Proceedings of the Russian Academy of Sciences. Geographical series, 2001, vol. 3, pp. 15-28.

4. Fartyshev A.I. Osobennosti pribrezhno-shelfovoy kriolitozony morya Laptevykh [Features of Laptev Sea coastal cryolithozone]. Novosibirsk, Nauka Publ., 1993. 136 p.

5. Schuur E.A.G., McGuire A.D., Schaedal C., Grosse G., Harden J.W., HayesD.J., Hugelius G., Koven C.D., Kuhry P., Lawrence D.M., Natali S.M., Olefeldt D., Romanovsky V.E., Schaefer K., Turetsky M.R., Treat C.C., Vonk J.E. Climate change and the permafrost carbon feedback. Nature, 2015, vol. 520, pp.171-179.

6. Vonk J.E., Gustafsson 0. Permafrost-carbon complexities. Nature Geoscience, 2013, vol. 6, no. 9, pp. 675-676.

7. Tarnocai C., Canadell J.G., Schuur E.A.G., Kuhry P., Mazhitova G., Zimov S. Soil organic carbon pools in the northern circumpolar permafrost region. Global Biogeochemical Cycles, 2009, vol. 23, GB2023.

8. Vetrov A.A., Romankevich E.A. Carbon Cycle in the Russian Arctic Seas. Berlin, Springer, 2004. 331 p.

9. Jeong S., Bloom A., Schimel D., Sweeney C., Parazoo N.C., Medvigy D., Schaepman-Strub G., Zheng C., Schwalm C.R., Huntzinger D.N., Michalak A.M., Miller C.E. Accelerating rates of Arctic carbon cycling revealed by long-term atmospheric $\mathrm{CO}_{2}$ measurements. Science Advances, 2018, vol. 4, no. 7, eaao1167.

10. McGuire A.D., Anderson L.G., Christensen T.R., Dallimore S., Guo L., Hayes D.J., Heimann M., Lorenson T.D., Macdonald R.W., Roulet N. Sensitivity of the carbon cycle in the Arctic to climate change. Ecological Monographs, 2009, vol. 79, no. 4, pp. $523-555$.

11. Shakhova N., Semiletov I., Sergienko V., Lobkovsky L., Yusupov V., Salyuk A., Salomatin A., Chernykh D., Kosmach D., Panteleev G., Nicolsky D., Samarkin V., Joye S., Charkin A., Dudarev 0., Meluzov A., Gustafsson Ö. The East Siberian Arctic Shelf: towards further assessment of permafrost-related methane fluxes and role of sea ice. Philosophical Transactions of the Royal Society A, 2015, vol. 373, 20140451.

12. Friedlingstein P. Carbon cycle feedbacks and future climate change. Philosophical Transactions of the Royal Society A, 2015, vol. $373,20140421$.

13. Tesi T., Semiletov I., Dudarev 0., Andersson A., Gustafsson Ö. Matrix association effects on hydrodynamic sorting and degradation of terrestrial organic matter during cross-shelf transport in the Laptev and East Siberian shelf seas. Journal of Geophysical Research. Biogeosciences, 2016, vol. 121, pp. 731-752.

14. Pugach S.P., Pipko I.I. Dynamics of colored dissolved matter on the East Siberian sea shelf. Doklady Earth Sciences, 2013, vol. 448 , no. 1, pp. 153-156.

15. Semiletov I., Pipko I., Gustafsson Ö., Anderson L.G., Sergienko V., Pugach S., Dudarev 0., Charkin A., Gukov A., Bröder L., Andersson A., Spivak E., Shakhova N. Acidification of East Siberian Arctic Shelf waters through addition of freshwater and terrestrial carbon. Nature Geoscience, 2016, vol. 9, pp. 361-365.

16. Shakhova N., Semiletov I., Gustafsson 0., Sergienko V., Lobkovsky L., Dudarev 0., Tumskoy V., Grigoriev M., Mazurov A., Salyuk A., Ananiev R., Koshurnikov A., Kosmach D., Charkin A., Dmitrevsky N., Karnaukh V., Gunar A., Meluzov A., Chernykh D. Current rates and mechanisms of subsea permafrost degradation in the East Siberian Arctic Shelf. Nature Communications, 2017, vol. 8, 15872 .

17. Contribution of Working Groups I, II and III to the Fourth Assessment Report of the Intergovernmental Panel on Climate Change. IPCC, 2007: Climate Change 2007: Synthesis Report. Eds. R.K. Pachauri, A. Reisinger. 2007. 104 p. Available at: https:// www.ipcc.ch/report/ar4/syr/ (accessed 06 October 2018).

18. Kattsov V.M., Källén E. Arctic Climate Impact Assessment (ACIA). Impacts of a warming arctic. Ch. 4: Future climate change: modeling and scenarios. Cambridge, Cambridge University Press, 2005. pp. 99-150.

19. Ulyantsev A.S., Lobkovsky L.I., Zhavoronkov A.V., Romankevich E.A. Problems of arctic shelf research: the experience from integrated geologic and geochemical studies in the Laptev sea. Oceanology, 2015, vol. 55, no. 6, pp. 919-925.

20. Vetrov A.A., Romankevich E.A. Interannual variability of the primary production and organic carbon fluxes in the Arctic seas of Russia. Oceanology, 2008, vol. 48, no. 3, pp. 340-348.

21. Tumskoy V.E. Termokarst i ego rol v razvitii regiona morya Laptevykh $v$ pozdnem pleystotsene $i$ golotsene. Avtoreferat Kand. nauk [Thermokarst and its role in Laptev Sea region development in late Pleistocene and Holocene. Cand. Diss. Abtsract]. Moscow, $2002.26 \mathrm{p}$.

22. Likht Ph.R. Struktura osadkov i fatsii Yaponskogo morya [Sediment structure and facies of Japan Sea]. Vladivostok, Far East Research Center Publ., 1983. 283 p.

23. Peters K.E., Walters, C.C., Moldowan, J.M. The Biomarker Guide. $2^{\text {nd }} \mathrm{ed}$. P. I. Biomarkers and Isotopes in the Environmental and $\mathrm{Hu}$ man History. Cambridge, Cambridge University Press, 2005. 387 p.

24. Peters K.E. Guidelines for evaluating petroleum source rock using programmed pyrolysis. American Association of Petroleum Geologists, 1986, vol. 70, pp. 318-329.

25. Disnar J.-R., Guillet B., Keravis D., Di Giovanni C., Sebag D. Soil organic matter (SOM) characterization by Rock-Eval pyrolysis: scope and limitation. Organic Geochemistry, 2003, vol. 34, pp. 327-343.

26. Melenevskii V.N., Leonova G.A., Konyshev A.S. The organic matter of the recent sediments of lake Beloe. Geology and Geophysics, 2011, vol. 52, no. 6, pp. 751-762.

27. Sebag D., Disnar J.-R., Guillet B., Di Giovanni C., Verrecchia E.P., Durand A. Monitoring organic matter dynamics in soil profi les by 'Rock-Eval pyrolysis': bulk characterization and quantification of degradation. European Journal of Soil Science, 2006, vol. 57, pp. 344-355.

28. Romanovskiy N.N., Gavrilov A.V., Tumskoy V.E., Holodov A.L. Termokarst i ego rol v formirovanii pribrezhnoy zony shelfa morya Laptevykh [Thermokarst and its role in formation of Laptev Sea coastal zone]. Earth Cryosphere, 1999, vol. III, no. 3, pp. $79-91$.

29. Cheverev V.G., Vidyapin I.Yu., Tumskoy V.E. Sostav i svoystva otlozheniy termokarstovykh lagun Bykovskogo poluostrova [Composition and properties of thermokarst lagoon sediments of Bykovsky Peninsula]. Earth Cryosphere, 2007, vol. XI, no. 3, pp. $44-50$.

30. Stein R., Macdonald R.W. Organic carbon budget: Arctic Ocean vs. Global Ocean. The organic carbon cycle in the Arctic Ocean. Eds. R. Stein, R.W. Macdonald. Berlin, Springer-Verlag, 2004. pp. 315-322.

31. Tissot B.P., Welte D.H. Petroleum Formation and Occurrence. Berlin, Springer-Verlag, 1984. 699 p.

32. Sapart C.J., Shakhova N., Semiletov I., Jansen J., Szidat S., Kosmach D., Dudarev 0., Van der Veen C., Egger M., Sergienko V., Salyuk A., Tumskoy V., Tison J.L., Rockmann T. The origin of methane in the East Siberian Arctic Shelf unraveled with triple isotope analysis. Biogeosciences, 2017, vol. 14, no. 9, pp. 2283-2292.

Received: 8 November 2018. 


\section{Information about the authors}

Elena V. Gershelis (Panova), assistant, National Research Tomsk Polytechnic University.

Ivan V. Goncharov, Dr. Sc., professor, National Research Tomsk Polytechnic University.

Oleg V. Dudarev, Dr. Sc., leading researcher, Pacific Oceanological Institute, Russian Academy of Sciences; researcher, National Research Tomsk Polytechnic University.

Alexey S. Ruban, Cand. Sc., assistant, National Research Tomsk Polytechnic University.

Tatyana G. Perevertaylo, Cand. Sc., associate professor, National Research Tomsk Polytechnic University.

Kseniya P. Shcherbakova, engineer, Pacific Oceanological Institute, Russian Academy of Sciences.

Natalia E. Shakhova, Dr. Sc., leading researcher, National Research Tomsk Polytechnic University.

Igor P. Semiletov, Dr. Sc., corresponding member of the Russian Academy of Sciences, head of the Laboratory, Pacific Oceanological Institute, Russian Academy of Sciences; professor, National Research Tomsk Polytechnic University. 